\title{
Analisis Pengaruh Pertanian Global terhadap Pelanggaran HAM (Studi Kasus Pertanian Rumah Kaca El Ejido)
}

\author{
Muhammad Ficky \\ 2015330187 \\ Mahasiswa Ilmu Hubungan Internasional, Fakultas Ilmu Sosial dan Ilmu Politik \\ Universitas Katolik Parahyangan
}

\begin{abstract}
According to the ancient Greek history, Gaia was the goddess of the earth. This concept reflected in traditional agriculture system that depends on nature and brings limitations. However, with the evolution of human's understanding of surrounding environment and natural resources has changed the way of agriculture. The creation of The World Trade Organization (WTO) appears to achieve free market and to removing all economic boundaries among nations through the free market. Subsequently, the concept of Food Security becomes important. This brings effect in agriculture sector where all nations increase their food production in order to compete in global market. As the consequences cultural and ecological diversity are considered as obstacles and exploited to achieve economic progress that leads to poverty and hunger. On the other hand, our environment will damage and no longer sustainable for our generation in the future. Along these lines, globalization does not always refer to overall development but also threatens human security. This paper will examine how globalized agriculture threatens human security in four parts. Firstly, it will give the highlight of globalized agriculture concept along with the explanation about Gaia theory that was formulated by James E. Lovelock. Then, it will examine the condition of greenhouse farm in Almeria, Spain. Furthermore, this paper will conclude the link between globalized agriculture and human security with Gaia theory point of view. In the end, this paper will purpose a solution for sustainable agriculture.
\end{abstract}

Keywords: Globalization, Agriculture, Human Security, Food Security

\section{Pendahuluan}

Seiring perkembangan zaman, globalisasi menjadi tidak terpisahkan dengan kehidupan manusia. Salah satunya ditandai dengan pembentukan World Trade Organization (WTO) pada tahun 1995 yang ditujukan untuk menciptakan perdagangan bebas dan menghapus batasan ekonomi antar negara serta mengubah

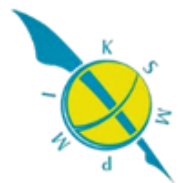


produksi dan konsumsi pangan secara global. ${ }^{1}$ Hal ini melahirkan konsep Globalized agriculture atau pertanian global yang mencoba memanfaatkan keuntungan dari globalisasi di bidang pertanian untuk mengurangi masalah kemiskinan dan menjaga aspek keamanan pangan. ${ }^{2}$ Makanan semakin mudah diperdagangkan secara internasional, sehingga turut mengubah praktik tata kelola pangan atau pertanian. Manusia tidak lagi mempertimbangakan aspek keseimbangan lingkungan sebagai faktor utama. Tujuan pertanian adalah menghasilkan kuantitas pangan yang besar dengan harga murah agar dapat diakses oleh seluruh lapisan masyarakat. Transisi tersebut menghasilkan masalah kemiskinan karena pertanian skala kecil tidak mampu bersaing dengan industri besar di pasar domestik maupun internasional. Pada tahun 2013, total petani di negara anggota Uni Eropa mengalami penurunan dari 12 juta menjadi 10,8 juta karena tidak mampu bersaing di pasar dunia yang didominasi oleh industri pangan multinasional. ${ }^{3}$ Selain itu, perluasan dan perubahan alih fungsi lahan yang digunakan untuk produksi pangan menyebabkan kerusakan lingkungan.

\section{Kerangka Teori}

Dalam mitologi Yunani kuno, Gaia digambarkan sebagai seorang dewi yang menjadi sumber kehidupan dan kematian atau sebuah entitas yang membentuk bumi. Filosofi Dewi Gaia lalu digunakan oleh James E. Lovelock, seorang ilmuwan dan ahli lingkungan dalam merumuskan Teori Gaia. Teori ekologis ini menyatakan bahwa biosfer dan komponen-komponen fisik Bumi (atmosfer; kriosfer; hidrosfer; dan litosfer) saling menyatu, membentuk interaksi yang menjaga iklim dan

\footnotetext{
${ }^{1}$ P. Oosterveer dan D.A. Sonnenfeld, "Food, globalization and sustainability", Earthscan, New York (2012)

2 The Fiber Optic Association. "Chapter 7: Globalization and the traditional role of agriculture." FOA.org. http://www.fao.org/docrep/005/y4671e/y4671e0c.htm (diakses pada 18 November 2017)

3 "EU frams and farmers in 2013: an update.", EU Agricultural and Farm Economics Briefs, https://ec.europa.eu/agriculture/sites/agriculture/files/rural-areaeconomics/briefs/pdf/009_en.pdf (diakses pada 18 November 2017)
} 
menyeimbangkan kehidupan di bumi. ${ }^{4}$ Teori Gaia memberikan gambaran bahwa Bumi adalah suatu entitas atau organisasi tunggal yang hidup dan bagian-bagiannya saling terhubung satu sama lain. Dalam bukunya, Lovelock juga menggambarkan bumi sebagai Spaceship Earth. Kehidupan di dalam pesawat ulang alik mengharuskan mendaur ulang energi agar dapat digunakan kembali untuk memenuhi kebutuhan hidup astronot selama berada di luar angkasa. Seperti sebuah kapal ulang alik, Bumi mengatur temperatur suhu; keseimbangan atmosfer; siklus hidrologi (daur ulang air); dan siklus lainya untuk menopang kehidupan makhluk hidup di dalamnya. ${ }^{5}$ Perumpamaan ini menandaskan bahwa Teori Gaia juga menumbuhkan kesadaran baru bahwa bumi dan aktivitas manusia saling memengaruhi. Oleh karena itu, manusia harus menjaga keseimbangan lingkungan agar Bumi dapat terus menopang kehidupan di dalamnya.

\section{Pembahasan}

Bergabungnya Spanyol dalam Uni Eropa dan WTO di tahun 1986 menjadi langkah awal dalam membuka akses besar ke pasar bebas. Di waktu yang sama pemerintah Spanyol mengintensifikasi sektor pertanian dan menjadi pengekspor bahan pangan terbesar di pasar dunia, khususnya Eropa. Kota El Ejido di Provinsi Almeria, sebelah Selatan Spanyol merupakan kota yang pertumbuhannya paling cepat setelah menjadi pusat produksi pertanian rumah kaca. Pada tahun 1998, usaha Pemerintah dalam mengamandemen Ley de Extranjería (Hukum tentang hak kebebasan dan orang asing) berhasil meningkatkan arus imigran ke Spanyol untuk mememnuhi kebutuhan tenaga kerja dengan biaya murah. ${ }^{6}$ Tenaga kerja imigran yang datang dari Eropa Timur, Maroko, Afrika dan Ekuador sebagian besar dipekerjakan di sektor kerja kasar seperti pertanian. Namun, tidak adanya regulasi

\footnotetext{
${ }^{4}$ James Lovelock, "Gaia: a new look at life on earth.", Oxford University Press (1979), http://www.markstoll.net/HIST4323/2011/Lovelock--Gaia.pdf

5 James Lovelock, "Gaia:a new look at life on earth"

6 "The remarkable case of Spanish immigration.", Bruegel, http://bruegel.org/2015/12/theremarkable-case-of-spanish-immigration/ (diakses pada 18 November 2017)
}

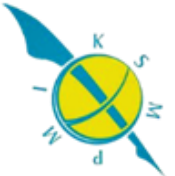


dari pemerintah terkait ketenagakerjaan dalam aktivitas produksi pertanian berkrontribusi menciptakan pekerjaan dengan upah rendah tanpa kontrak kerja yang jelas. Hal ini berakibat pada tidak adanya kesejahteraan kerja, sulitnya mengakses kebutuhan pokok, seperti tempat tinggal maupun jaminan kesehatan dan harus menghadapi marginalisasi sosial karena perbedaan budaya serta agama. Masalah lain timbul setelah Spanyol mengalami krisis ekonomi pada tahun 2005. Ketidakmampuan petani untuk membayar upah dan tunjangan pekerja buruh yang tinggi berdampak pada semakin mudahnya imigran ilegal masuk ke Spanyol sebagai tenaga kerja sementara. Kemiskinan dan diskriminasi rasial menjadi fenomena yang lekat dialami oleh para imigran.

Menurut data yang diperoleh dari Koordinator Palang Merah di Almeria, Francisco Vicente, terdapat sekitar 15.000 sampai 20.000 migran tunawisma di provinsinya, dimana sekitar 5.000 orang tinggal di rumah dan gubuk tanpa fasilitas sanitasi air dan listrik. ${ }^{7}$ Keadaan ini dipicu oleh semakin tingginya arus migrasi internasional ke Spanyol. Akibatnya, imigran mulai membangun gubuk kardus di dekat lahan-lahan pertanian karena tidak adanya bantuan yang diberikan dari pemerintah atau petani sekitar sampai mereka mendapatkan pekerjaan. Masalah kesehatan juga menjadi permasalahan umum yang dialami para imigran. Penyakit seperti Tuberkulosis, AIDS dan hepatitis banyak menjangkit mereka karena sulitnya mendapatkan bantuan medis yang layak. Orang-orang yang sakit akan ditinggalkan dan diisolasi di rumah pertanian serta berujung pada kematian. Hal ini juga berdampak pada munculnya tensi antara imigran dengan petani lokal. Pada tahun 2000, terjadi tindak kriminalitas yang dilakukan oleh imigran kepada petani sebagai bentuk protes. Tetapi karena tidak memiliki surat kependudukan yang lengkap, para imigran tidak mendapatkan bantuan hukum dan berujung sebagai tahanan penjara. Ketidakadilan ini semakin mengancam keamanan dan kesejahteraan mereka.

7 "Spain's salad growers are modern-day slaves, say charities", The Guardian, https://www.theguardian.com/business/2011/feb/07/spain-salad-growers-slaves-charities (diakses pada 18 November 2017)

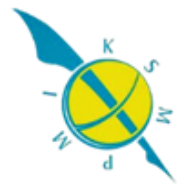




\section{Pembalasan dari Dewi Gaia}

Apabila dikaji melalui Teori Gaia, usaha manusia untuk memenuhi keamanan pangan mengakibatkan ketidakseimbangan bagi lingkungan. Negara berusaha memenuhi aspek keamanan pangan dengan memproduksi bahan pangan dalam jumlah besar dengan harga murah. Hal ini berdampak pada pengorbanan kesejahteraan dan keamanan para pekerja imigran. Permasalahan timbul karena keadaan pasar global yang menekan harga bahan pangan tetap rendah selama krisis ekonomi di Spanyol, sementara biaya untuk bahan bakar dan pupuk semakin tinggi. Untuk mengendalikan biaya produksi, petani melakukan pemotongan upah dan tidak memberikan jaminan sosial kepada para pekerja imigran. Kenyataannya Pemerintah Spanyol turut mengambil andil dalam memindahkan imigran ke pusatpusat pertanian tanpa membuat regulasi yang jelas dan mengancam para imigran dengan deportasi jika mengeluhkan kondisi kerja mereka kepada pihak lain. Tidak adanya perhatian dari pemerintah dan pemilik lahan pertanian terhadap kesejahteraan pekerja imigran menetapkan kasus ini sebagai pelanggaran hak asasi manusia. Kejadian yang terjadi di El Ejido ini dapat dilihat sebagai saksi perbudakan di abad ke-21. Manusia tidak lagi melihat pentingnya relasi antara tindakan mereka dengan alam yang berimbas pada terancamnya keamanan manusia.

\section{Kesimpulan}

Sejak ribuan tahun lalu manusia secara tidak langsung menerapkan Teori Gaia dalam kehidupan sehari-hari. Teori ini menumbuhkan kesadaran bahwa bumi dan aktivitas manusia saling memengaruhi sehingga manusia memiliki keharusan dalam menjaga keseimbangan lingkungan agar Bumi dapat terus menopang kehidupan di dalamnya. Namun, seiring perkembangan zaman, globalisasi menjadi tidak terpisahkan dengan kehidupan manusia. Peningkatan jumlah penduduk dunia yang drastis berimbas pada tingginya permintaan pangan. Hal ini memberikan perubahan pada sistem produksi pangan. Kasus pertanian rumah kaca El Ejido

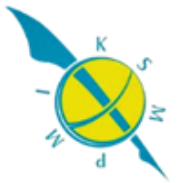


menjadi sebuah gambaran ketidakseimbangan lingkungan dimana manusia tidak lagi melihat pentingnya relasi antara tindakan mereka dengan alam yang berimbas pada terancamnya keamanan manusia. Kurangnya regulasi terkait pertanian dan tidak adanya perhatian dari pemerintah Spanyol dan pemilik lahan pertanian terhadap kesejahteraan pekerja imigran berimbas pada pelanggaran terhadap kemanusian. Oleh karena itu, diperlukan penelitian lebih lanjut untuk menemukan penerapan sistem pertanian berwawasan lingkungan sebagai upaya mengatasi permasalahan tersebut. Agroecology adalah sebuah disiplin ilmu dengan mengacu pada prinsip-prinsip dasar ekologis dapat menjadi salah satu solusi. Teori ini mencoba mencari inovasi sistem pertanian berkelanjutan yang dapat mengoptimalkan hasil panen dan memelihara kesejahteraan petani, sebagai contoh sistem pertanian organik atau sistem pertanian berbasis keluarga. ${ }^{8}$ Melalui teori ini, manusia akan kembali sadar bahwa pertanian bukan sekadar proses produksi pangan tetapi sebuah relasi antar manusia, komunitas dan alam yang kaya akan aspek kebudayaan sehingga akan muncul keseimbangan.

8 "Family Farming Knowledge Platform.", Food and Agriculture Organization of the United Nations, http://www.fao.org/family-farming/themes/agroecology/en/_(diakses pada 8 Desember 2017)

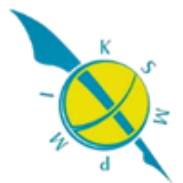

